\title{
Improved fluorescent (calcium indicator) dye uptake in brain slices by blocking multidrug resistance transporters
}

\author{
Ivan Manzini ${ }^{\mathrm{a}, \mathrm{b}, *}$, Tina-Saskia Schweer ${ }^{\mathrm{a}}$, Detlev Schild ${ }^{\mathrm{a}, \mathrm{b}}$ \\ ${ }^{a}$ Department of Neurophysiology and Cellular Biophysics, University of Göttingen, Humboldtallee 23, 37073 Göttingen, Germany \\ ${ }^{\mathrm{b}}$ DFG Research Center for Molecular Physiology of the Brain (CMPB), University of Göttingen, \\ Humboldtallee 23, 37073 Göttingen, Germany
}

Received 15 June 2007; received in revised form 18 July 2007; accepted 23 July 2007

\begin{abstract}
ATP-binding cassette $(\mathrm{ABC})$ transporters are a family of transmembrane proteins that, also known as multidrug resistance proteins, transport a wide variety of substrates across biological membranes in an energy-dependent manner. Recently it has been shown that members of this protein family interfere with fluorescent (calcium indicator) dye uptake in taste buds of rat and in cells in the olfactory epithelium of larval Xenopus laevis, including olfactory receptor neurons. It has, however, not been resolved whether this effect only serves to extrude xenobiotics in sensory taste and olfactory cells, or alternatively, whether it is a more general feature of many central nervous system neurons. In the latter case blocking these transporters would improve fluorescent dye uptake in general. Here we show, by means of cell imaging, that also neurons of the olfactory bulb express multidrug resistance transporters, whereby a marked inhomogeneity among cells in the main and accessory olfactory bulb was observed. Blocking these transporters improved the net uptake of fluorescent dyes not only in cell somata of the olfactory bulb, but especially in fine neuronal structures such as individual dendrites or olfactory glomeruli, which consist of a tangle of tiny neuronal processes. We therefore suggest that the expression of multidrug resistance proteins may be common in cells of the central nervous system, and that the application of specific transport inhibitors could generally improve fluorescent dye uptake in brain slices, thereby improving calcium imaging conditions.
\end{abstract}

(C) 2007 Elsevier B.V. All rights reserved.

Keywords: Main olfactory bulb; Accessory olfactory bulb; Neurons; Fluorescent dyes; Multidrug resistance transporters

\section{Introduction}

The ATP-binding cassette (ABC) transporter superfamily is among the largest protein superfamilies known (Dean and Allikmets, 1995; Klein et al., 1999; Linton and Higgins, 2007). ABC transporters utilize the energy of ATP hydrolysis to pump a wide variety of molecules across extra- and intracellular membranes (Higgins, 1992; Childs and Ling, 1994; Dean et al., 2001; Linton and Higgins, 2007). Their substrates include phospholipids, ions, peptides, steroids, polysaccharides, amino acids, organic anions, bile acids, drugs and other xenobiotics (Higgins, 1992; Borst and Elferink, 2002; Zarubica et al., 2007; Herget and Tampe, 2007; Stieger et al., 2007; Nies and Keppler, 2007). ABC transporters involved in the transport of xenobiotics include but

\footnotetext{
* Corresponding author at: Department of Neurophysiology and Cellular Biophysics, University of Göttingen, Humboldtallee 23, 37073 Göttingen, Germany. Tel.: +49 551 397639; fax: +49 551398399 .

E-mail address: imanzin@gwdg.de (I. Manzini).
}

are not limited to P-glycoprotein (Pgp), multidrug resistance associated proteins (MRPs) and the breast cancer resistance protein (BCRP) (Borst and Elferink, 2002).

In addition to these effects, some $\mathrm{ABC}$ transporters could have a profound technical impact upon the quality and feasibility of cellular imaging measurements because a number of fluorescent dyes are among their substrates. Specifically, the Pgp and the MRPs are known to be involved in the transmembrane transport of several fluorescent dyes, including calcium sensitive dyes in a number of cultured cell lines (Homolya et al., 1993, 1996; Bredzden et al., 1994; Essodaigui et al., 1998; Prechtl et al., 2000; Olson et al., 2001; Elliott et al., 2004), in cells of isolated segmental ganglia of the leech (Munsch and Deitmer, 1995) as well as in taste buds (Jakob et al., 1998) and in cells in the olfactory epithelium of larval Xenopus laevis (Manzini and Schild, 2003). It has also been shown that different cell types of the mouse cerebellum take up a fluorescent calcium dye differentially (Kirischuk and Verkhratsky, 1996). Finally, it has been reported that in rat taste buds and in the olfactory epithelium of larval X. laevis the expression of Pgp and MRPs severely 
interferes with the successful performance of calcium imaging experiments (Jakob et al., 1998; Manzini and Schild, 2003).

At this point an important question arises. Is the extrusion of fluorescent dyes via multidrug resistance transporters limited to the above mentioned cell types or not? Here we follow and confirm the latter hypothesis taking tissue slices of the main olfactory bulb (MOB) and accessory olfactory bulb (AOB) of larval X. laevis as an example for central neurons and MK571, a specific inhibitor of MRP transporters (Gekeler et al., 1995; Abrahamse and Rechkemmer, 2001) as transport blocker. Our results show that multidrug resistance transporters are functional and vary in their fluorescent dye extrusion capacity in different parts of the central nervous system (CNS). This suggests that blocking these transporters enhances fluorescent dye uptake and, therefore, could improve the outcome of various calcium imaging studies in the CNS.

\section{Materials and methods}

\subsection{Slice preparation}

Tadpoles of X. laevis (stage 51-54, staged after Nieuwkoop and Faber, 1994) were anaesthetized and immobilized in a mixture of ice and water. The animals were then sacrificed in accordance with the Göttingen University Committee for Ethics in Animal Experimentation. A block of tissue containing the olfactory mucosae, the olfactory nerves and the anterior twothirds of the brain including the MOB and the AOB were cut out and kept in bath solution having the following composition (in $\mathrm{mM}$ ): $98 \mathrm{NaCl}, 2 \mathrm{KCl}, 1 \mathrm{CaCl}_{2}, 2 \mathrm{MgCl}_{2}, 5$ glucose, 5 Na-pyruvate, 10 HEPES; 230 mOsmol, pH 7.8. This is the physiological $\mathrm{pH}$ in this poikilothermal species at room temperature (Howell et al., 1970). The tissue block was glued onto the stage of a vibroslicer (VT 1000S, Leica, Bensheim, Germany) and only the dorsal surface of the block was sliced off. Thereby the cutting angle was chosen in a way to enter the olfactory bulb (OB) approximately above the olfactory nerve entrance. This way we obtained 200-250 $\mu \mathrm{m}$ thick slices with direct access to the MOB and AOB.

\subsection{Transporter measurements with fluorescent dyes}

The slices were fixed in a recording chamber with a grid (Edwards et al., 1989) and the AM-esters of the fluorescent dyes and the transport inhibitor were added dissolved in bath solution. We used fura-red/AM, calcein/AM and fura-2/AM as fluorescent dyes and potential transporter substrates, and MK571 as a specific inhibitor of MRP transporters (Gekeler et al., 1995; Abrahamse and Rechkemmer, 2001). The dyes were dissolved in DMSO and Pluronic F-127 and used at a final concentration of $50 \mu \mathrm{M}$ (fura-red and fura-2) or $500 \mathrm{nM}$ (calcein). MK571 was dissolved in distilled water ( $10 \mathrm{mM}$ stock) and used at final concentrations of 10-200 $\mu \mathrm{M}$. The fluorescent dyes used as well as Pluronic F-127 were purchased from Molecular Probes (Leiden, The Netherlands) and MK571 was purchased from Alexis Biochemicals (Grünberg, Germany). All other chemicals were from Sigma (Deisenhofen, Germany).
To observe the amount of dye loading we used either an Axiovert 100M (Zeiss, Jena, Germany) to which a laser scanning unit (LSM 510, Zeiss, Jena, Germany) was attached, or an Axioskop 2 (Zeiss, Göttingen, Germany) with a CCD camera attached (Micromax, Visitron, München, Germany). The fluorescence intensities of fura-red and calcein were measured using the LSM 510 (excitation at 488 for both dyes; emission $>505 \mathrm{~nm}$ for calcein and $>585 \mathrm{~nm}$ for fura-red). The fluorescence intensity of fura- 2 was measured using the Axioskop 2 in combination with the CCD camera (excitation at $380 \mathrm{~nm}$; emission $500-530 \mathrm{~nm}$ ). In the experiments where the time course of dye loading of fura-red or calcein was observed the recording chamber was placed on the microscope stage and the recording was started approximately 2 min after the beginning of incubation. The images were acquired using the LSM 510. The progressive increase in fluorescence in the slice was measured by taking an image every $3 \mathrm{~min}$ (in case of fura-red) or every minute (in case of calcein). The fluorescence images were evaluated by calculating intensity histograms and average intensities, leaving out all pixels not covered by the slice. Thus, the intensities shown in this paper are averages over all pixels covering the slice and can adopt values from 0 to 255 (8 bit). Accordingly, we give the fluorescence in these units per minute. In Fig. 5a, for example, the increases were $3.6 / 42 \mathrm{~min}=0.09 \mathrm{~min}^{-1}$ and $18 / 42 \mathrm{~min}=0.45 \mathrm{~min}^{-1}$ during the control and MK571 phase, respectively.

\section{Results}

When an OB slice of a $X$. laevis tadpole (Fig. 1a) was incubated in bath solution containing the fluorescent calcium sensitive dye fura-red/AM for $30 \mathrm{~min}$, the cells of the OB showed only a weak fura-red fluorescence (Fig. 1b). Under these or similar staining conditions: (i) relatively high excitation light intensities have to be used leading to fast bleaching and deterioration of the preparation and (ii) fine structures such as dendrites cannot be imaged at all. Using much longer dye incubation periods is neither an option because this, too, would lead to a deterioration of the preparation and recording conditions. Fig. 1c shows the same OB slice after additional $30 \mathrm{~min}$ with MK571 $(100 \mu \mathrm{M})$ added to the incubation solution. MK571 is a specific inhibitor of MRP transporters (Gekeler et al., 1995; Abrahamse and Rechkemmer, 2001). Clearly, the staining during the second $30 \mathrm{~min}$ was more effective. The intensity histograms shown on the right hand side of the respective image (see Section 2) underwent a marked right-shift during the second $30 \mathrm{~min}$ of incubation. When repeating the above experiment with the fluorescent dye calcein, the fluorescence of which is independent of $\left[\mathrm{Ca}^{2+}\right]_{i}$, we obtained similar results (Fig. 1d and e). The improvement in staining with fura-red and calcein by adding MK571 to the incubation solution was confirmed in a total of 10 and 12 slices, respectively. We never observed a comparable marked right-shift of fura-red or calcein intensity histograms, when OB slices were incubated without MK571 not only during the first but also the second $30 \mathrm{~min}$ of an experiment (data not shown). When OB slices that underwent the above experimental procedures were viewed at lower magnification and a 
(a)

(b)

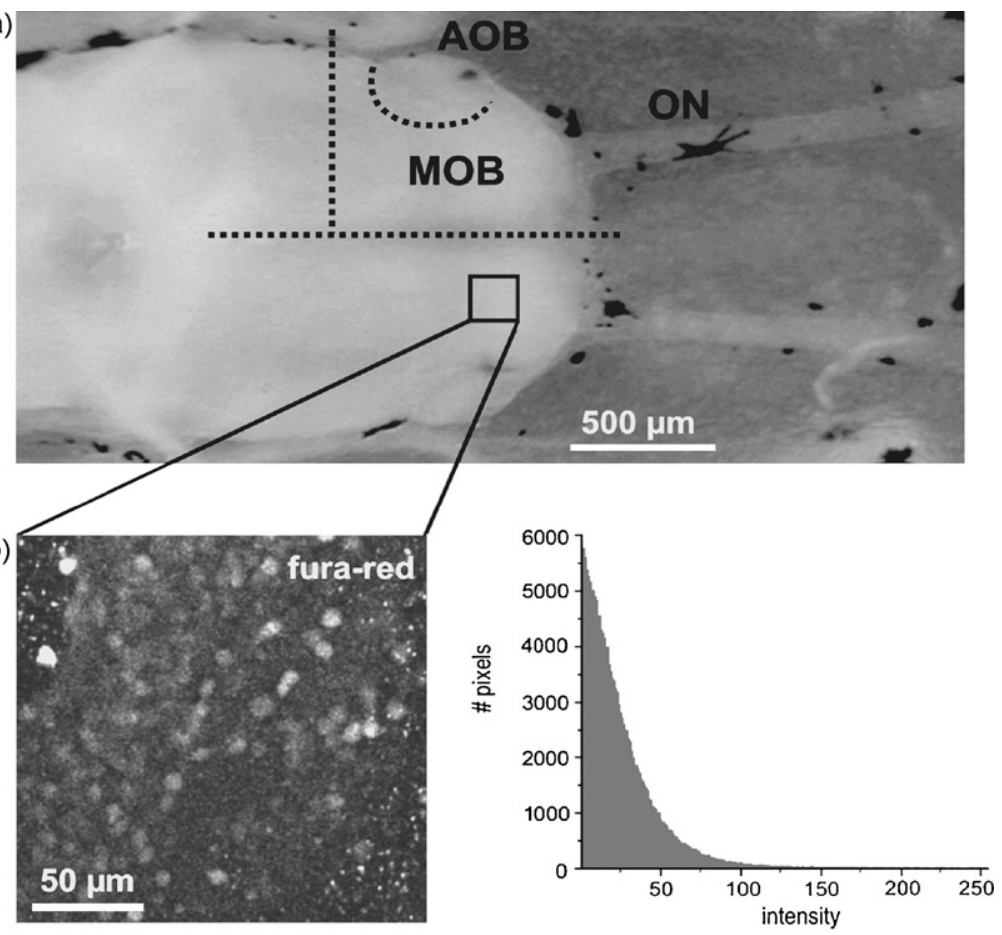

(c)
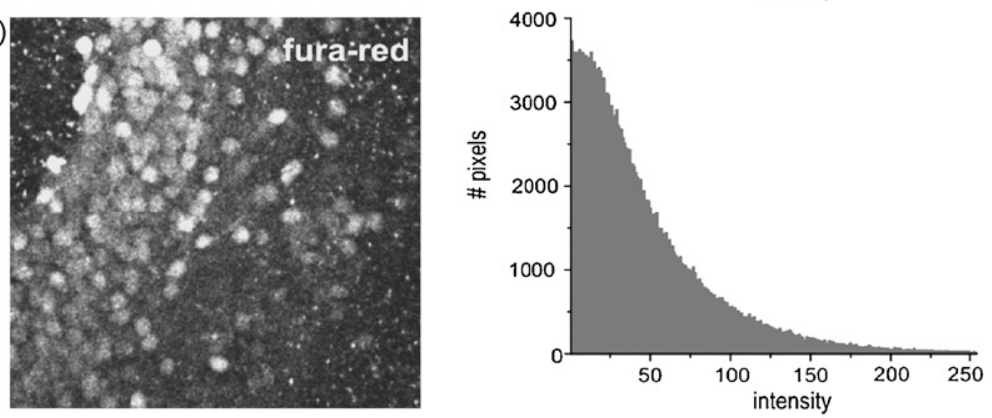

(d)
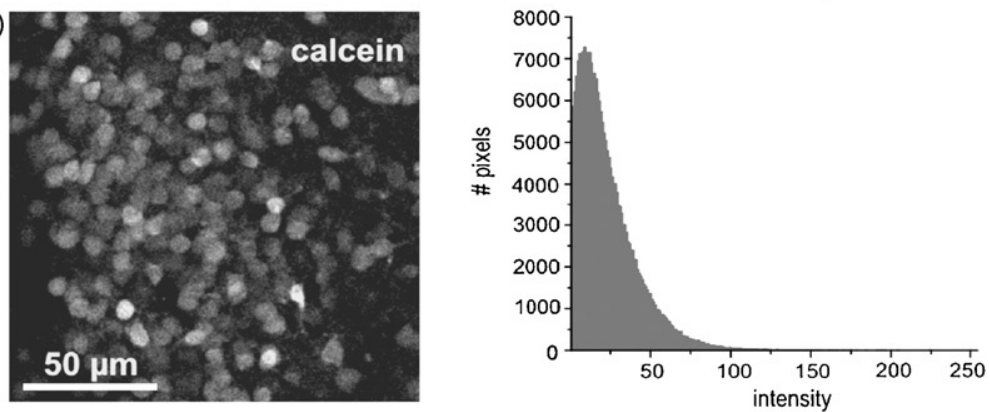

(e)
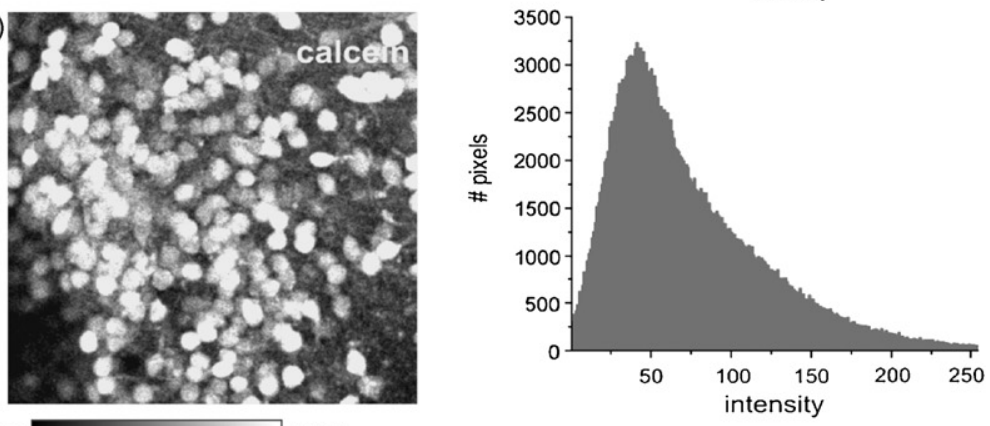

0

255 

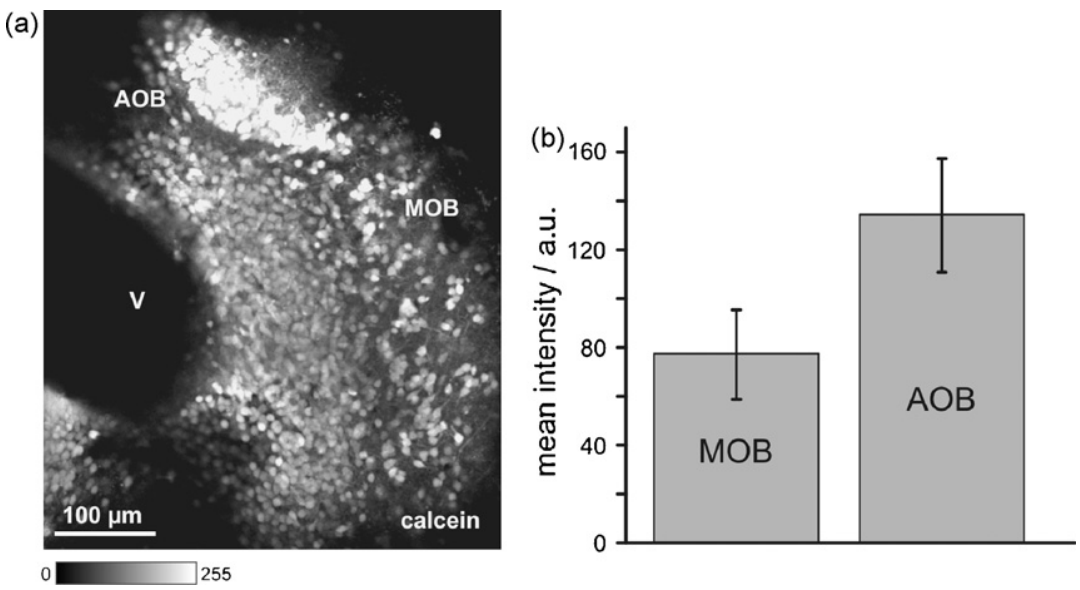

Fig. 2. Differential uptake of fluorescent dye in cells of the main and accessory olfactory bulb. (a) Overview over a slice of the OB of larval Xenopus laevis (MOB, main olfactory bulb; AOB, accessory olfactory bulb and V, ventricle) after incubation of $60 \mathrm{~min}$ in calcein/AM (500 nM). (b) Histogram showing the average intensity of the pixels ( \pm S.D.) covering the MOB and $\mathrm{AOB}$ of 10 individual larvae. Bar scales from low (0, black) to high (255, white) fluorescence intensities.

larger field of view, it was obvious that the cells of the AOB were always stained more intensely than the cells of the MOB (Fig. 2a, calcein staining). In a total of $10 \mathrm{OBs}$ the intensity of pixels covering the MOB was $77.4 \pm 17.98$ (mean \pm S.D.; Fig. 2 b), whereas the intensity of pixels covering the AOB was $134.4 \pm 22.86$ (mean \pm S.D.; Fig. 2b).

The effects of the transporter blocker, in particular with respect of the fine structures of the tissue, can be seen best when incubating two slices of the same kind with and without MK571 simultaneously, rather than successively as above, all other staining conditions identical. Fig. 3a (calcein) clearly shows dendritic fibers and, specifically, olfactory glomeruli, both of which can hardly ever be seen without using MK571 (Fig. 3b). An increased staining of OB slices under MK571 occurred not only with calcein/AM incubation (observed in five slices), but also with fura-red/AM incubation (six slices; Fig. $3 \mathrm{c}$ and $\mathrm{d}$ as control) and fura-2/AM incubation (four slices; Fig. $3 e$ and $f$ as control).

In order to identify the necessary MK571 concentrations for obtaining optimal stainings, we incubated different slices with different concentrations of MK571 using the $\left[\mathrm{Ca}^{2+}\right]_{\mathrm{i}-}$ independent dye calcein. Fig. 4a shows five MOB slices each incubated in calcein/AM for 30 min but with different concentrations of MK571 $(0-200 \mu \mathrm{M})$ added. The cells of the MOB slices incubated in calcein/AM without or with $10 \mu \mathrm{M}$ MK571 showed very low fluorescence intensities, whereas MK571 at $50 \mu \mathrm{M}$ clearly showed and improved cell staining. While $100 \mu \mathrm{M}$ MK571 additionally enhanced cell staining, no clear further improvement could be reached with $200 \mu$ M MK571. This becomes apparent from Fig. 4b, where the mean fluores- cence cell intensities of the slices shown in Fig. 4a are plotted as a function of the MK571 concentrations used. Fig. $4 \mathrm{c}$ then extends the information given in Fig. $4 \mathrm{~b}$ by showing average intensities ( \pm S.D.) of 25 slices ( 5 slices for each concentration), plotted as a function of the MK571 concentrations used. Clearly the effect of MK571 saturates at a concentration of approximately $100 \mu \mathrm{M}$.

In order to investigate the time course of staining in more detail we took images at constant time intervals while incubating the slice in fura-red/AM or calcein/AM and represented the intensities $I(t)$ averaged over the slice as a function of time. We thereby made two sets of experiments, one focusing at cells in the MOB and one focusing at cells in the AOB. This way we were able to survey the differences between MOB and AOB. In cells in the MOB the average intensities $I(t)$ of fura-red increased very slowly if the transport-inhibitor was not present (Fig. 5a, from $t=0$ to $42 \mathrm{~min}$ ). In the example shown the fluorescence increase was approximately $0.09 \mathrm{~min}^{-1}$ without MK571 and approximately $0.45 \mathrm{~min}^{-1}$ with MK571 $(100 \mu \mathrm{M})$ added. The net uptake was five-fold faster with the blocker, i.e. the net uptake ratio was 5 . In 13 identically performed fura-red incubation experiments in the MOB we found an average net uptake ratio of $3.50 \pm 1.27$ (mean \pm S.D.). Fig. $5 \mathrm{~b}$ shows the average fura-red intensity dynamics $I(t)$ of cells of the AOB. In the example shown the fluorescence increase was $0.38 \mathrm{~min}^{-1}$ without MK571 and $0.95 \mathrm{~min}^{-1}$ with MK571 $(100 \mu \mathrm{M})$ added. The net uptake ratio was thus 2.50 [average net uptake ratio of $2.06 \pm 0.65$ (mean \pm S.D.), $n=12$ ]. In four individual cells randomly selected from a slice of the OB, MK571 $(100 \mu \mathrm{M})$ had the same effect on the net uptake of fura-red, yielding uptake

Fig. 1. Effect of MK571 on the uptake of fluorescent dyes in the olfactory bulb. (a) Overview over the anterior part of the brain including the OB and the olfactory nerve of larval Xenopus laevis (ON, olfactory nerve; MOB, main olfactory bulb and AOB, accessory olfactory bulb). (b and c) Laser scanning images of a part of the MOB incubated in a solution containing $50 \mu \mathrm{M}$ fura-red/AM, first for $30 \mathrm{~min}$ without MK571 and then for 30 min following addition of $100 \mu \mathrm{M}$ MK571 to the bath. Images were taken after $30 \mathrm{~min}$ (b) and $60 \mathrm{~min}$ (c). The panels to the right of the figures show the intensity histograms of the corresponding images. Pixels that were not covered by the slice were not considered for calculating the histograms. ( $d$ and e) Laser scanning images of a comparable part of the MOB as in (b and c) incubated with $500 \mathrm{nM}$ calcein/AM, first for $30 \mathrm{~min}$ without MK571 (d) and then with MK571 (100 $\mu \mathrm{M}$; e) and their respective intensity histograms. Bar scales from low (0, black) to high (255, white) fluorescence intensities. 
ratios in the range between 4.48 and 7.33 (Fig. 5c). The net uptake curves of fura-red show a linear time course. However, if calcein was used as fluorescent dye, the uptake curves deviated markedly from linearity. They saturated and could rather be described by an exponential function (Fig. 6a, MOB and Fig. 6b, AOB), a kinetic behaviour also observed and well explained in taste bud cells and cells in the olfactory epithelium (Jakob et al., 1998; Manzini and Schild, 2003). Addition of MK571 increased the calcein uptake in the same range as seen for fura-red.

From a practical point of view it is important to know whether dye that entered a cell under MK571 in its AM-form, stays, in its salt form, within the cell after the washout of MK571. We analyzed this question by recording the fluorescence of fura-red after substitution of the loading solution (i.e. $50 \mu \mathrm{M}$ fura-red/AM and $100 \mu \mathrm{M}$ MK571) with standard bath solution (see Section 2). Fig. 7 shows fluorescence images 0 and $36 \mathrm{~min}$ after completion of dye loading and changing to standard bath solution. The average fluorescence intensities clearly stayed approximately at the same level. Virtually identical results were obtained with three other slices treated the same way as the slice shown in Fig. 7.

\section{Discussion}

We first observed an enhanced dye uptake by addition of MK571 in olfactory sensory neurons (Manzini and Schild, 2003) (a)

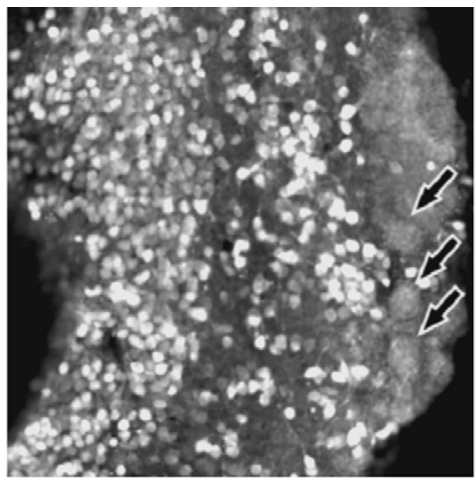

(c)

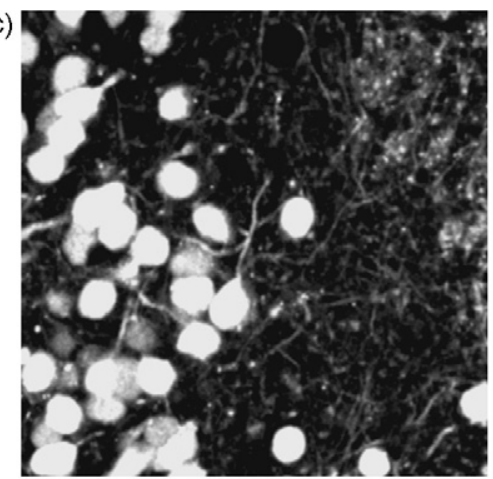

(e)

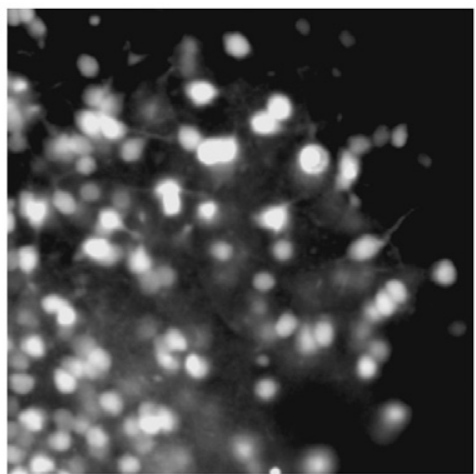

(b)

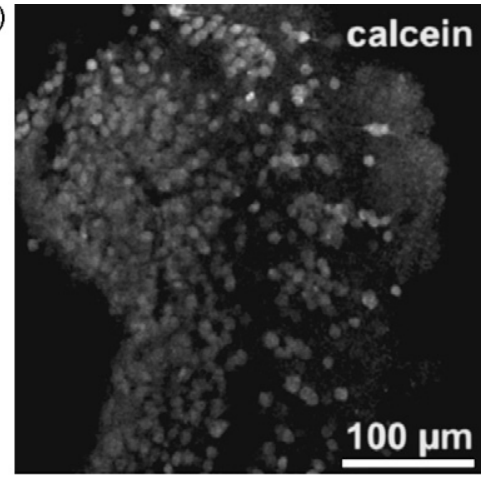

(d)

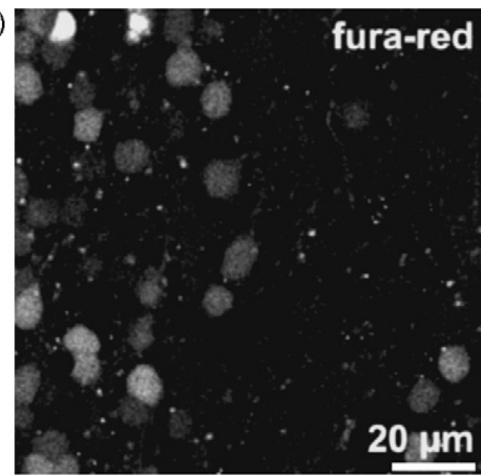

(f)

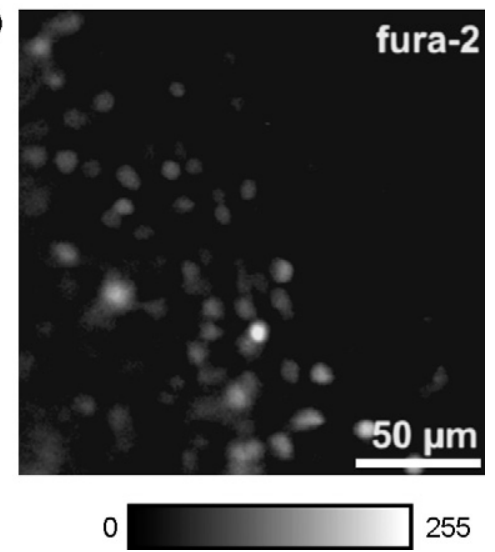

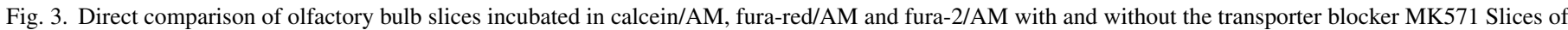

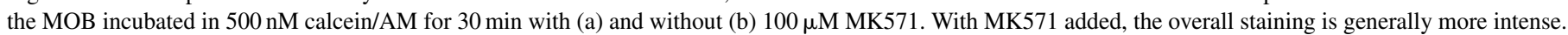





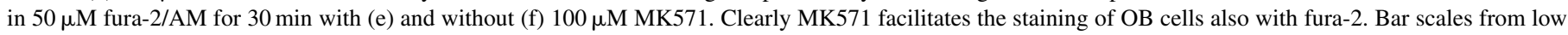
$(0$, black) to high $(255$, white $)$ fluorescence intensities. 
(a)
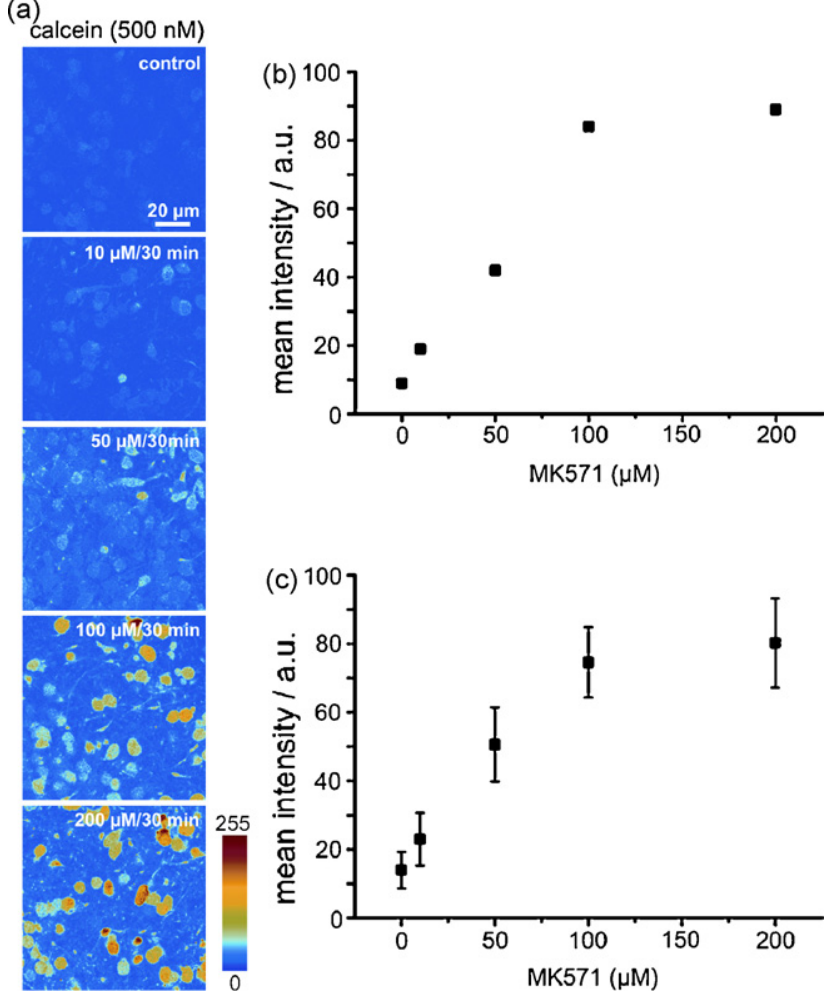

Fig. 4. Dose-response relationship for the effect of MK571 on fluorescent dye loading. (a) Differential fluorescent dye loading in cells of five MOB slices incubated in $500 \mathrm{nM}$ calcein/AM for $30 \mathrm{~min}$ with different concentrations of MK571 (0-200 $\mu \mathrm{M})$ added to the bath solution. Bar scales from low (0, blue) to high (255, red) fluorescence intensities. (b) Mean fluorescence intensities of the cells covering the MOB slices shown in part (a) of this figure plotted as a function of the MK571 concentrations used. (c) Mean fluorescence intensities $( \pm$ S.D.) of cells of 25 different MOB slices ( 5 slices for each concentration) plotted as a function of the MK571 concentrations used.

which had also been observed in taste bud cells (Jakob et al., 1998). However, it remained unclear whether or not this finding was characteristic for and limited to sensory cells in the sense of xenobiotic removal across their plasma membranes. Here we provide evidence that fluorescent (calcium indicator) dye uptake in CNS neurons can be significantly improved by the application of a blocker of MRPs such as MK571. In practical terms this means that in many fluorescent (calcium) dye imaging studies the recording conditions may be improved. Note that this is particularly true in cases where the experimenter has not considered this possibility because the results so far obtained appeared satisfactory and did not openly call for improvement. Nonetheless, in these cases, applying an MRP transporter blocker during dye-ester loading would have the advantage of shorter slice incubation duration (and thus a fresher preparation) and of a better observability of fine cellular processes such as dendrites and spines. It is probably useful and important to note that we have found that MK571 improves also the uptake of the commonly used calcium indicator dye fluo-4/AM (see Manzini et al., 2007). As fluo-4 is very little fluorescent before $\mathrm{Ca}^{2+}$ binding it is not suitable for dye loading experiments as shown in this paper, but the salt of fluo-4, just as fura-red (see Fig. 7), does not appear to be extruded out of cells of OB slices after substitution of
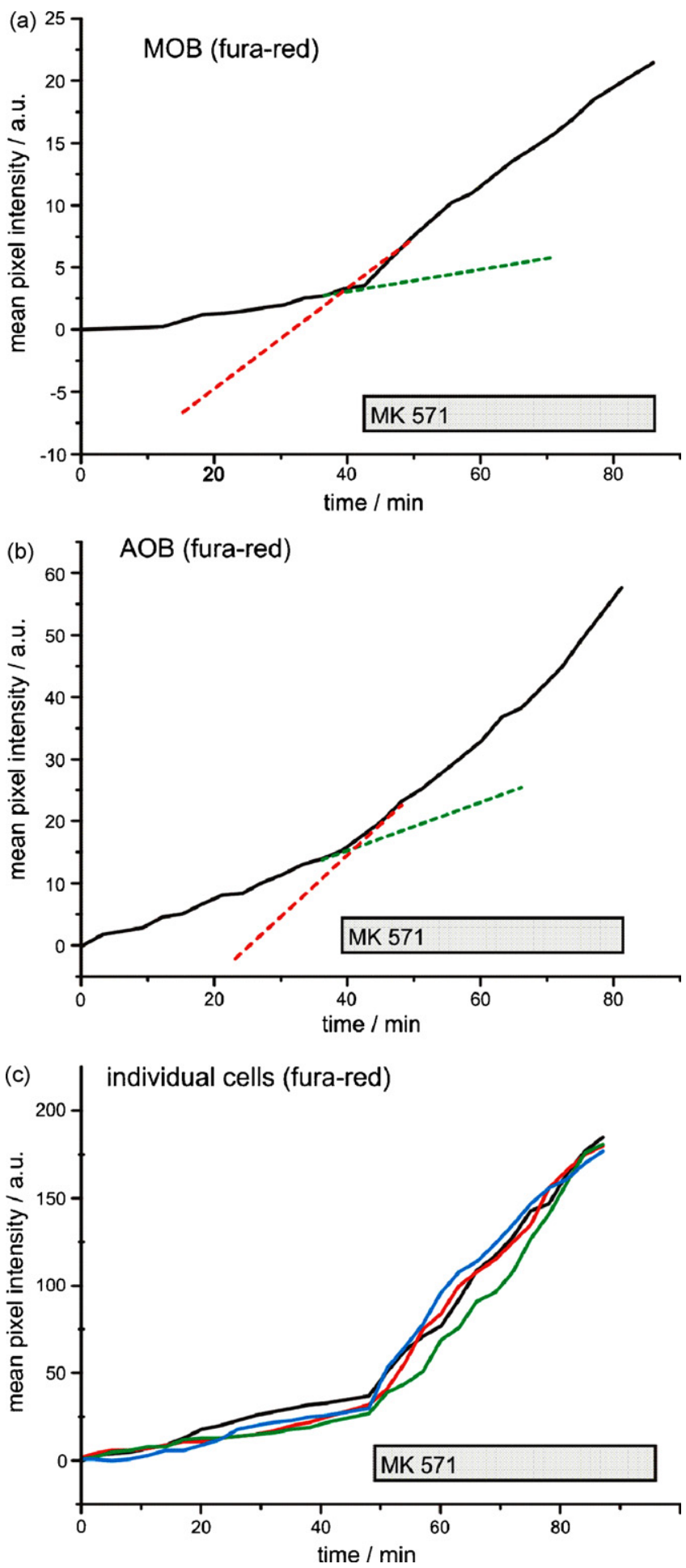

Fig. 5. Time courses of fura-red accumulation in olfactory bulb slices (MOB and $\mathrm{AOB}$ ) in the absence and presence of MK571 OB slices were incubated in $50 \mu \mathrm{M}$ fura red/AM. The bars under the traces show the time over which MK571 was added to the incubation solution. The concentration of fura red/AM was kept constant over the whole incubation. Effects of $100 \mu \mathrm{M}$ MK571 in the MOB (a) and AOB (b). The dotted lines are extensions of regression lines fitted to the experimental data (green, fura-red alone; red, with MK571 added). (c) Fura-red accumulation in four individual cells of the MOB before and after application of $50 \mu \mathrm{M}$ MK571. 



Fig. 6. Nonlinear time course of calcein accumulation without and with MK571 OB slices were incubated in bath solution containing $500 \mathrm{nM}$ calcein/AM. The bars under the traces show the time over which MK571 was added to the incubation solution. The concentration of calcein/AM was kept constant over the whole incubation. Effects of $100 \mu \mathrm{M}$ MK571 (a, MOB) and $100 \mu \mathrm{M}$ MK571 (b, AOB). Virtually identical results were obtained from 21 (MOB) and 17 (AOB) slices treated in the same manner as described above.
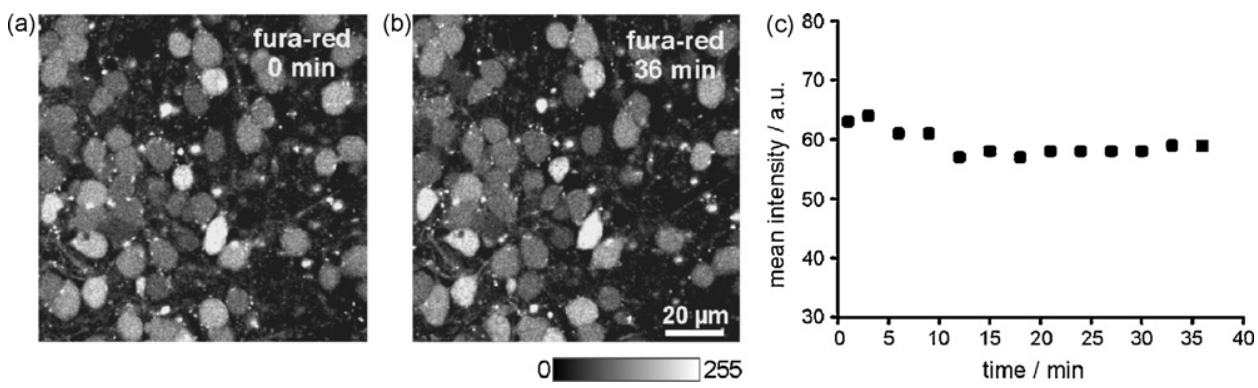

Fig. 7. The salt of fura-red stays in cells of MOB slices after removal of MK571 Image of an MOB slice taken immediately after completion of dye loading (a) and after $36 \mathrm{~min}$ in standard bath solution (b). (c) Fluorescence of the MOB slice monitored over $36 \mathrm{~min}$ by taking images every $3 \mathrm{~min}$.

the loading solution with standard bath solution (see Manzini et al., 2007). It is therefore unnecessary to constantly supply MK571 with the bath solution while doing calcium imaging experiments.

\section{Acknowledgement}

This work was supported by a grant of the DFG Research Center Molecular Physiology of the Brain (CMPB) to I.M. and D.S.

\section{References}

Abrahamse SL, Rechkemmer G. Identification of an organic anion transport system in the human colon carcinoma cell line HT29 clone 19A. Pflugers Arch 2001;441:529-37.

Borst P, Elferink RO. Mammalian ABC transporters in health and disease. Annu Rev Biochem 2002;71:537-92.

Bredzden CB, Hedley DW, Rauth AM. Constitutive expression of P-glycoprotein as a determinant of loading with fluorescent calcium probes. Cytometry 1994; 17:343-8.

Childs S, Ling V. The MDR superfamily of genes and its biological implications. Important Adv Oncol 1994:21-36.

Dean M, Allikmets R. Evolution of ATP-binding cassette transporter genes. Curr Opin Genet Dev 1995;5:779-85.

Dean M, Rzhetsky A, Allikmets R. The human ATP-binding cassette (ABC) transporter superfamily. Genome Res 2001;11:1156-66.
Edwards FA, Konnerth A, Sakmann B, Takahashi T. A thin slice preparation for patch clamp recordings from neurones of the mammalian central nervous system. Pflugers Arch 1989;414:600-12.

Elliott JI, Raguz S, Higgins CF. Multidrug transporter activity in lymphocytes. Br J Pharmacol 2004;143:899-907.

Essodaigui M, Broxterman HJ, Garnier-Suilerot A. Kinetic analysis of calcein and calcein-acetoxymethylester efflux mediated by the multidrug resistance protein and P-glycoprotein. Biochemistry 1998;37:2243-50.

Gekeler V, Ise W, Sanders KH, Ulrich WR, Beck J. The leukotriene LTD4 antagonist MK571 specifically modulates MRP associated multidrug resistance. Biochem Biophys Res Commun 1995;208:345-52.

Herget M, Tampe R. Intracellular peptide transporters in human-compartmentalization of the "peptidome". Pflugers Arch 2007;453:591-600.

Higgins CF. ABC transporters: from microorganisms to man. Annu Rev Cell Biol 1992;8:67-113.

Homolya L, Hollo Z, Germann UA, Pastan I, Gottesman MM, Sarkadi B. Fluorescent cellular indicators are extruded by the multidrug resistance protein J Biol Chem 1993;268:21493-6.

Homolya L, Hollo M, Muller M, Mechetner EB, Sarkadi B. A new method for a quantitative assessment of $\mathrm{P}$-glycoprotein-related multidrug resistance in tumour cells. Br J Cancer 1996;73:849-55.

Howell BJ, Baumgardner FW, Bondi K, Rahn H. Acid-base balance in coldblooded vertebrates as a function of body temperature. Am J Physiol 1970;18:600-6.

Jakob I, Hauser IA, Thévenod F, Lindemann B. MDR1 in taste buds of rat vallate papilla: functional, immunohistochemical, and biochemical evidence. Am J Physiol 1998;274:182-91.

Kirischuk S, Verkhratsky A. $\left[\mathrm{Ca}^{2+}\right]_{i}$ recordings from neural cells in acutely isolated cerebellar slices employing differential loading of the 
membrane-permeant form of the calcium indicator fura-2. Pflugers Arch 1996;431:977-83.

Klein I, Sarkadi B, Varadi A. An inventory of the human ABC proteins. Biochim Biophys Acta 1999;1461:237-62.

Linton KJ, Higgins CF. Structure and function of ABC transporters: the ATP switch provides flexible control. Pflugers Arch 2007;453:555-67.

Manzini I, Schild D. Multidrug resistance transporters in the olfactory receptor neurons of Xenopus laevis tadpoles. J Physiol 2003;546:375-85.

Manzini I, Brase C, Chen TW, Schild D. Response profiles to amino acid odorants of olfactory glomeruli in larval Xenopus laevis. J Physiol 2007;581:567-79.

Munsch T, Deitmer JW. Maintenance of fura-2 fluorescence in glial cells and neurons of the leech central nervous system. J Neurosci Methods 1995;57:195-204
Nies AT, Keppler D. The apical conjugate efflux pump ABCC2 (MRP2). Pflugers Arch 2007;453:643-59.

Nieuwkoop PD, Faber J.Nieuwkoop PD, Faber J, editors. Normal table of Xenopus laevis (Daudin). New York and London: Garland Publishing Inc.; 1994.

Olson DP, Taylor BJ, Ivy SP. Detection of MRP functional activity: calcein $\mathrm{AM}$ but not BCECF AM as a multidrug resistance-related protein (MRP1) substrate. Cytometry 2001;46:105-13.

Prechtl S, Roellinghoff M, Scheper R, Cole SP, Deeley RG, Lohoff M. The multidrug resistance protein 1: a functionally important activation marker for murine Th1 cells. J Immunol 2000;164:754-61.

Stieger B, Meier Y, Meier PJ. The bile salt export pump. Pflugers Arch 2007;453:611-20.

Zarubica A, Trompier D, Chimini G. ABCA1, from pathology to membrane function. Pflugers Arch 2007;453:569-79. 